\title{
Clinical Outcome of CABG on Off-pump Beating Heart and On-pump Beating Heart: Experience in Ibrahim Cardiac Hospital \& Research Institute (ICHRI)
}

\author{
Md. Sharif Hasan, ${ }^{1}$ Abdul Hamid, ${ }^{2}$ Sirajul Islam, ${ }^{3}$ Tanvir Ahmed, ${ }^{4}$ Arman E Wadud ${ }^{5}$
}

\begin{abstract}
Background: To avoid harmful effect of cardiopulmonary bypass (CPB) used in off-pump coronary artery bypass graft (CABG) surgery, cardiac surgeons are now inclined to on-pump beating heart surgery (ONBEAT). However, the superiority of ONBEAT over Off-pump has not yet been conclusively established. This study compares the outcomes between off-pump and on pump beating heart CABG surgery.
\end{abstract}

Methods: A total 249 consecutive patients who underwent non-emergency, primary isolated CABG from January 2014 to December 2017 by a single surgeon were included. The selected patients were assigned to either OPCAB group (Patients who received Off-pump beating heart CABG surgery, $n=193$ ) or to ONBEAT group (patients who received On-pump beating heart CABG surgery, $n=56)$. The clinical outcomes were investigated and compared.

Result: Forty percent of the patients were in their $5^{\text {th }}$ decade of life. A male predominance was also observed. The two study groups were almost identical in terms of age and $\operatorname{sex}(p=0.983$ and $p=0.153$ respectively). None of the conventional risk factors of ischemic heart disease (smoking, diabetes, hypertension and dyslipidaemia) were any different between the study groups $(p>0.05)$. Cerebrovascular disease, recent MI, congestive heart failure and left main disease were significantly higher in the on-pump beating heart group compared to those in the off-pump beating heart group $(p<0.05)$. The left ventricular ejection fraction (LVEF) was significantly lower in the former group than that in the latter group $(p=0.007)$. Both groups required 3 grafts on an average. Two patients in the on-pump group required Intra-Aortic Balloon Pump (IABP) support as opposed to none in the off-pump group $(p=0.050)$. The mean cardiopulmonary bypass (CPB) time was $105.8 \pm 46.5$ in the on-pump group. Fourteen patients ( $25 \%$ ) from off-pump group needed urgent switching to on-pump group. Postoperative drainage in the first 24 hours was significantly voluminous in the on-pump group $(p<0.001)$. The incidence of pneumonia, respiratory failure, arrhythmia, renal failure requiring haemodialysis and perioperative MI were significantly higher in the on-pump group $(p<0.001, p<0.001, p=0.037, p<0.001$ and $p=0.050$ respectively). The patients with prolonged mechanical ventilation were also more in the on-pump group. The left ventricular ejection fraction (LVEF) was much lower and Intensive Care Unit (ICU) stay was longer in the on-pump group compared to those in the off-pump group ( $p<$ $0.001)$. The incidence of in-hospital mortality was also higher in the former group $(p=0.037)$.

Conclusion: OPCAB was associated with lower operative morbidity compared to ONBEAT cardiac surgery. However, the increased morbidity in ONBEAT group might have been influenced by a sizable proportion of patients from OPCAB group being switched to ONBEAT group due to their haemodynamic deterioration and frequent ventricular fibrillation. But on-pump CABG can be performed safely on high risk patients. Use of cardiopulmonary bypass and elimination of cardioplegic arrest may be beneficial to hemodynamically unstable patients.

Key words: Clinical Outcome, CABG, Off-pump Beating Heart, On-pump Beating Heart etc.

\section{Authors' information:}

${ }^{1}$ Dr. Md. Sharif Hasan, Senior Consultant, and Associate Professor, Department of Cardiac Surgery, Irahim Cardiac Hospital \& Research Institute (ICHRI)

2 Prof. Lt. Col (Retd.) Dr. Md. Hamidur Rahman, Senior Consultant, Head of the Department Cardiac Anaesthesiology, Ibrahim Cardiac Hospital \& Research Institute (ICHRI)

${ }^{3}$ Dr. Md. Sirajul Islam, Senior Consultant and Associate Professor, Department of Cardiac Anaesthesiology, Ibrahim Cardiac Hospital \& Research Institute (ICHRI)

${ }^{4}$ Dr. Syed Tanvir Ahmed, Assistant Professor and Associate Consultant, Department of Cardiac Surgery, Ibrahim Cardiac Hospital \& Research Institute (ICHRI)

${ }^{5}$ Dr. Md. Armane Wadud, Assistant Professor and Associate Consultant, Department of Cardiac Surgery, Ibrahim Cardiac Hospital \& Research Institute (ICHRI)

Correspondence: Dr. Md Sharif Hasan, Phone: +8801711344467 E-mail:drsharifhasan@yahoo.com 


\section{INTRODUCTION}

Coronary artery bypass graft (CABG) surgery is the preferred revascularization strategy for multi-vessel coronary artery disease. However, it is not without risk of mortality and severe morbidity. Although the first coronary artery bypass graft (CABG) procedures were performed in the 1960 on beating heart, refinement of the cardiopulmonary bypass pump led to the widespread use of this technology for CABG surgery beginning in 1968. However, various complications of CABG surgery including cerebral injury \& stroke,,$^{1,2}$ perioperative renal dysfunction,,$^{3,4}$ systemic inflammatory response $^{5}$ myocardial dysfunction ${ }^{6} \&$ pulmonary complication 7,8 attributed to cardiopulmonary bypass pump in the past few decades have prompted cardiac surgeons to re-examine the safety and efficacy of CABG surgery performed on a beating heart. 9,10 Off pump CABG surgery (OPCAB) refers to $C A B G$ performed typically with sternotomy, without cardiopulmonary bypass, on a beating heart. In the United States the society of thoracic surgeons (STS) reported an off-pump CABG frequency of 9.9\% between 1998 and 1999 but this proportion had increased to $25 \%$ for isolated CABG in 2001. ${ }^{11}$ The proportion of OPCAB in CABG dramatically increased up to $63 \%$ in 2008 according to the annual report from Japanese association for cardiac surgery. ${ }^{12}$ This is because off-pump CABG has been developed along with the advancement in devices ${ }^{13}$ to avoid deleterious effects of extracorporeal circulation. ${ }^{14}$ However, there might be a tendency for cardiac surgery to choose on- pump beating CABG in high risk patients, especially in patients with hemodynamic instability. ${ }^{15}$

Despite avoiding the disadvantages resulting from cardioplegic arrest and aortic cross clump, on-pump beating heart CABG is associated with post-operative morbidities related to the use of cardio-pulmonary bypass. ${ }^{16}$ The systematic inflammatory reaction initiated by the extracorporeal circuit results in mechanical trauma to blood, activation of various immunological cascades (compliment, cytokines), impaired homeostasis, neurological, renal \& gastrointestinal dysfunction. ${ }^{17}$ Furthermore, aortic cannulation and CPB can result in micro- and macro-embolization, with subsequent neurological and other end-organ injuries, including global myocardial ischemia, reperfusion injury etc. ${ }^{18}$ That purpose the present study was intended to compare the outcome between off-pump beating heart and on-pump beating heart CABG in order to determine which of the two procedures is better in terms of short-term outcome.

\section{METHODS:}

This single center prospective study was conducted on 249 consecutive patients who underwent non-emergency isolated CABG surgery by a single surgeon at Ibrahim Cardiac Hospital \& Research Institute between January 2014 to December 2017. The patients had graftable double or triple vessel disease. Exclusion criteria included concomitant left ventricular aneurysm, concomitant post infarction. ventricular septal defect, concomitant moderate to severe mitral regurgitation \& aortic regurgitation and concomitant acquired or congenital cardiac or aortic surgery. The patients were divided into 2 groups Group-I, who were operated on without cardiopulmonary bypass (OPCAB group) \& Group-II who received on-pump beating heart CABG surgery or (ONBEAT group). The decision to perform on-pump beating or off-pump beating CABG was influenced by each patient's demographic and clinical profile (e.g. age, diabetes mellitus, renal dysfunction, left ventricular ejection fraction and estimated surgical risk) but the final choice was dependent on discretion of the cardiac surgeon, since in our center, off-pump CABG has been performed routinely for over 6 years.

All off-pump and on-pump beating CABG procedures were performed by a single surgeon who is highly experienced in both off-pump and on-pump beating CABG surgery. Data pertaining to peroperative, intraoperative \& post-operative variables (age, sex, weight, smoking, hypertension, diabetes, hyperlipidaemia, cerebrovascular disease (CVD), chronic obstructive pulmonary diseases (COPD), chronic heart failure, renal dysfunction, recent myocardial infarction, extent of coronary artery disease, peripheral vascular disease, left main disease, history of myocardial infarction, left ventricular ejection 
fraction, congestive heart failure etc.) were collected using a structured questionnaire. The main outcome measures were in-hospital mortality, IABP (as and when needed basis), neurological deficit (stroke), post-operative renal failure, pneumonia, duration of ventilator support, drainage during first 24 hours, perioperative MI, length of ICU stay.

In-hospital mortality was defined as death within the same hospital in which the CABG was done regardless of causes. Postoperative neurological deficit was defined as a new focal neurological deficit \& comatose states occurring postoperatively and persisted for $>24$ hours after its onset and was noted before discharge. Post-operative myocardial infarction was defined as appearance of a new Q-wave during postoperative period in two or more contiguous leads on an Electrocardiogram or significant rise in postoperative cardiac enzymes. Postoperative bleeding was defined as bleeding that required surgical re-exploration in operating theater. Intraoperative low cardiac output syndrome was defined as the requirement for intraaortic balloon pump (IABP). Post-operative pneumonia was defined as presence of pathogenic microorganism in sputum culture requiring antibiotics or an X-ray chest diagnosing pneumonia following cardiac surgery. Prolonged ventilation was defined as mechanical ventilation (MV) $>12$ hours. Post-operative respiratory failure was defined as duration of mechanical ventilation for more than 72 hours or reintubation following cardiac surgery. Wound infection was considered if any drainage material or discharge from the sternotomy wound was purulent. Patients were installed with an IABP when they were unable to discontinue cardiopulmonary bypass or developed low cardiac output after CABG surgery.

Statistical analysis was performed with SPSS (Statistical Package for Social Sciences), version 17. Categorical data were expressed as frequency with corresponding percentage, while continuous data were presented as mean value $\pm \mathrm{SD}$, or median and range. Dichotomous variables were compared between study groups using Chi-square $\left(\chi^{2}\right)$ Test and continuous variables were compared using Student's $\mathrm{t}$-Test. The level of significance was set at $5 \%$ and a probability value ( $p$-value) of $<0.05$ was considered significant.

\section{SURGICAL PROCEDURE:}

All patients underwent CABG through median full sternotomy, the in situ left internal mammary artery. The procedure is always preferred as the first choice for revascularization of the left anterior descending coronary artery territory. Saphenons vein graft was harvested with an open technique. For patients receiving off-pump CABG, heparin was given to reach activated clotting time (ACT) of more than 300 second. The central temperature was maintained above $36^{\circ} \mathrm{C}$ to avoid hypothermia induced ventricular arrhythmia. The heart was displaced using a posterior pericardial sling and gauze swabs. For good presentation of the target arteries on the lateral and inferior aspect of the heart patients were placed in right decubitus Trendelenburg position. Stabilization of target coronary arteries was accomplished with this stabilizer. A CO2 blower was used for a bloodless field. An intra-coronary shunt was used in all patients to maintain coronary flow thereby reducing myocardial ischemia \& at the same time minimizing bleeding from the coronary arteriotomy.

For patients undergoing on-pump beating heart CABG, cardiopulmonary bypass was instituted by cannulating the ascending aorta and right atrium after systemic heparinization ( $3 \mathrm{mg} / \mathrm{kg}$ body weight) with a target activated clotting time more than 400s without either cardioplegic arrest or an aortic cross-clamp. Moderate haemodilution (hamatocrit 20 to $25 \%$ ) and no cooling were used during cardiopulmonary bypass. Standard management included membrane oxygenators, arterial catheter filters \& a non-palsatile flow of $2.4 \mathrm{~L} / \mathrm{min} / \mathrm{m}^{2}$ with a mean arterial blood pressure greater than $60 \mathrm{~mm} \mathrm{Hg}$. The same exposure, stabilization and immobilization technique were used to allow exposure of the lateral, posterior and inferior walls of the heart during grafting. The left anterior descending (LAD) artery was usually grafted first, for the grafting of this artery was achieved without much displacement of the heart and without much hemodynamic compromise. Distal anastomosis was performed with continuous 7-0 or 8-0 polypropylene (prolene) 
monofilament suture. Proximal anastomosis was performed with 6-0 continuous prolene suture. After discontinuation of cardiopulmonary bypass heparin was neutralized with $1 \mathrm{mg}$ protamine sulphate per $1 \mathrm{~kg}$ provided.

\section{RESULTS:}

Forty percent of the patients were in their $5^{\text {th }}$ decade of life. A male predominance was also observed. The two study groups were almost identical in terms of age and sex $(p=0.983$ and $p=0.153$ respectively) (Table I). None of the conventional risk factors of ischemic heart disease (smoking, diabetes, hypertension \& dyslipidaemia) were any different between the study groups ( $p>0.05)$. Cerebrovascular disease, recent MI, congestive heart failure and left main disease were significantly higher in the on-pump beating heart group compared to that in the off-pump beating heart group $(p<0.05)$. The left ventricular ejection fraction (LVEF) was significantly lower in the former group than that in the latter group ( $p=0.007$ ) (Table II). Both groups required 3 grafts on an average. Two patients in the on-pump group required IABP support as opposed to none in the off-pump group $(p=0.050)$. The mean cardiopulmonary bypass (CPB) time was $105.8 \pm$ 46.5 in the on-pump group. Fourteen patients (25\%) from off-pump group needed urgent switching to on-pump group (Table III).

\begin{tabular}{|c|c|c|c|}
\hline \multirow{2}{*}{$\begin{array}{l}\text { Demographic } \\
\text { characteristics* }\end{array}$} & \multicolumn{2}{|c|}{ Group } & \multirow[b]{2}{*}{$p$-value } \\
\hline & $\begin{array}{c}\text { On-pump } \\
(\mathrm{n}=56)\end{array}$ & $\begin{array}{r}\text { Off-pump } \\
(n=193)\end{array}$ & \\
\hline \multicolumn{4}{|l|}{ Age $^{*}$ (years) } \\
\hline$<50$ & $13(23.2)$ & $44(22.8)$ & 0.983 \\
\hline $50-60$ & $22(39.3)$ & $78(40.4)$ & \\
\hline$\geq 60$ & $21(37.5)$ & $71(36.8)$ & \\
\hline \multicolumn{4}{|l|}{ Sex } \\
\hline Male & $47(83.9)$ & 175(90.7) & 0.153 \\
\hline Female & $9(16.1)$ & $18(9.3)$ & \\
\hline
\end{tabular}

Figures in the parentheses indicate corresponding \%; *Chi-squared Test $\left(\chi^{2}\right)$ was done to analyze the data.
TABLE II. Distribution of risk factors and clinical characteristics between groups

\begin{tabular}{|c|c|c|c|}
\hline \multirow{2}{*}{$\begin{array}{l}\text { Risk factors and clinical } \\
\text { characteristics }\end{array}$} & \multicolumn{2}{|c|}{ Group } & \multirow[b]{2}{*}{ p-value } \\
\hline & $\begin{array}{c}\text { On-pump } \\
(\mathrm{n}=56)\end{array}$ & $\begin{array}{c}\text { Off-pump } \\
(\mathrm{n}=193)\end{array}$ & \\
\hline Recent smoking* & $13(23.2)$ & $34(17.6)$ & 0.346 \\
\hline Hypertension* & $40(71.4)$ & $141(73.1)$ & 0.810 \\
\hline Diabetes* & $34(60.7)$ & $123(63.7)$ & 0.681 \\
\hline Overweight \& obese & $52(53.6)$ & $88(45.6)$ & 0.599 \\
\hline Hyperlipemia/DL* & $47(83.9)$ & $156(80.8)$ & 0.599 \\
\hline Cerebrovascular disease (CVD) * & $4(7.1)$ & $2(1.0)$ & 0.009 \\
\hline Peripheral vascular disease ${ }^{* *}$ & $0(0.0)$ & $2(1.0)$ & 0.600 \\
\hline Chronic pulmonary disease (COPD)* & $3(5.4)$ & $11(5.7)$ & 0.922 \\
\hline S. Creatinine (Pre-operative) * & $1.2 \pm 0.3$ & $1.1 \pm 0.3$ & 0.074 \\
\hline Chronic heart failure* & $14(25.0)$ & $30(15.5)$ & 0.102 \\
\hline Recent $\mathrm{Ml}^{*}$ & $32(57.1)$ & $74(38.3)$ & 0.012 \\
\hline Congestive heart failure* & $7(12.5)$ & $8(4.1)$ & 0.021 \\
\hline \multicolumn{4}{|l|}{ Extent of $C A D^{*}$} \\
\hline 1 vessel & $0(0.0)$ & $10(5.2)$ & 0.082 \\
\hline 2 or more vessel & $56(100.0)$ & 183(94.8) & \\
\hline LM disease* & 19(33.9) & $41(21.2)$ & 0.051 \\
\hline $\operatorname{LVEF}(\%)^{\#}$ & $49.4 \pm 8.6$ & $53.2 \pm 9.2$ & 0.007 \\
\hline
\end{tabular}

Figures in the parentheses indicate corresponding \%; *Chi-squared Test $\left(\chi^{2}\right)$ was done to analyze the data. \# Data were analyzed using Unpaired t-Test and were presented as mean \pm SD.

**Fisher's Exact Test was done to analyzed the data.

\section{TABLE III. Comparison of peroperative findings between} groups

\begin{tabular}{lccc} 
& \multicolumn{2}{c}{ Group } & \\
\cline { 2 - 3 } $\begin{array}{l}\text { Peroperative } \\
\text { variables }\end{array}$ & $\begin{array}{c}\text { On-pump } \\
(\mathrm{n}=56)\end{array}$ & $\begin{array}{c}\text { Off-pump } \\
(\mathrm{n}=193)\end{array}$ & p-value \\
\hline Number of grafts & $3.1 \pm 0.6$ & $2.8 \pm 0.8$ & 0.407 \\
IABP support** & $2(3.6)$ & $0(0.0)$ & 0.050
\end{tabular}

Figures in the parentheses indicate corresponding \%; \# Data were analyzed using Unpaired t-Test and were presented as mean \pm SD.

**Fisher's Exact Test was done to analyze the data.

Postoperative drainage in the first 24 hours was significantly voluminous in the on-pump group than that in off-pump group ( $p<0.001$ ). The incidence of pneumonia, respiratory failure, arrythmia, renal failure requiring haemodialysis and perioperative MI were significantly higher in the former group $(p<0.001 . p<0.001, p=0.037$, 
$p<0.001$ and $p=0.050$ respectively). The patients with prolonged mechanical ventilation were also more in the former group [mechanical ventilation $(M V)>12$ hours]. The left ventricular ejection fraction (LVEF) was much lower and ICU stay was longer in the on-pump group compared to those in the off-pump group ( $<0.001)$. The incidence of in-hospital mortality was also higher in the on-pump group ( $p=0.037$ ) (Table IV).

\begin{tabular}{|c|c|c|c|}
\hline \multirow[b]{2}{*}{ Outcome variables } & \multicolumn{2}{|c|}{ Group } & \multirow[b]{2}{*}{$\mathrm{p}$-value } \\
\hline & $\begin{array}{c}\text { On-pump } \\
(\mathrm{n}=56)\end{array}$ & $\begin{array}{c}\text { Off-pump } \\
(\mathrm{n}=193)\end{array}$ & \\
\hline Drainage in first $24 \mathrm{~h}(\mathrm{ml})^{\#}$ & $384.9 \pm 103.7$ & $195.3 \pm 71.2$ & $<0.001$ \\
\hline Pneumonia* & $15(26.8)$ & $3(1.6)$ & $<0.001$ \\
\hline Respiratory failure* & $13(23.2)$ & $4(2.1)$ & $<0.001$ \\
\hline Stroke** & $0(0.0)$ & $1(0.5)$ & 0.775 \\
\hline Arrythmia** & $21(37.5)$ & $2(1.0)$ & $<0.001$ \\
\hline Mediastinitis** & $1(1.8)$ & $0(0.0)$ & 0.225 \\
\hline Renal failure needing hemodialysis** & $3(5.4)$ & $1(0.5)$ & 0.037 \\
\hline Duration of MV $(>12 \mathrm{~h})^{*}$ & $35(62.5)$ & $4(2.1)$ & $<0.001$ \\
\hline LVEF before discharge $(\%)^{\#}$ & $50.0 \pm 9.1$ & $56.5 \pm 8.0$ & $<0.001$ \\
\hline ICU stay (days)\# & $3.8 \pm 1.3$ & $3.4 \pm 0.8$ & 0.007 \\
\hline Perioperative-MF** & $2(3.6)$ & $0(0.0)$ & 0.050 \\
\hline In-hospital mortality** & $3(5.4)$ & $1(0.5)$ & 0.037 \\
\hline
\end{tabular}

Figures in the parentheses indicate corresponding \%; ${ }^{*}$ Chi-squared Test $\left(\chi^{2}\right)$ was done to analyze the data. \# Data were analyzed using Unpaired t-Test and were presented as mean \pm SD.

**Fisher's Exact Test was done to analyzed the data.

\section{DISCUSSION:}

There is continuing debate as to impact of OPCAB on CABG operative mortality. Studies suggest that OPCAB has a protective effect. ${ }^{8,19}$ Our analysis also showed that intraoperative conversion from OPCAB to ONBEAT had increase in operative mortality. This finding is consistent with previous studies that reported higher mortality in patients undergoing conversion from OPCAB to ONBEAT CABG surgery. ${ }^{20-22}$ The process of conversion itself may confer an increased risk of complication. However, as this study reported the experience of a single-center, single surgeon and, therefore, may not be generalizable.
Due to hemodynamic deterioration and frequent ventricular fibrillation during off-pump CABG surgery 14 patients had to be switched urgently to on-pump beating heart CABG surgery. Out of 14 patients 2 died of low cardiac output and malignant arrhythmia and 1 patient died due to pneumonia in the postoperative period. Several authors have, however, reported that hemodynamic collapse and emergent conversion to cardiopulmonary bypass from off-pump CABG is associated with poor prognosis. ${ }^{23}$

The major finding of this study was that patients in OPCAB group compared to the ONBEAT group received decreased amount of drainage during the first 24 hours, and a more improved left ventricular ejection fraction (LVEF), decreased in-hospital mortality and reduced incidence of major operative morbidity; while ONBEAT group because of increased amount of drainage during first 24 hours required blood transfusion. The reason may be related to cardiopulmonary bypass and more heparinization during on-pump beating CABG surgery. The ONBEAT group compared to the OPCAB had a higher incidence of postoperative pulmonary complication like pneumonia, which might be related to the application of extracorporeal circulation during on-pump beating heart surgery. The risk and severity of acute lung injury have been consistently linked to the duration of CPB. Severe lung injury following CPB has been associated with a $50 \%$ mortality. ${ }^{24}$

Lesser degree of lung injury after CPB such as reduced oxygen index, increased ventilation perfusion mismatch and decreased lung compliance are seen in up to $12 \%$ of patients. Pulmonary injury is detectable even following uncomplicated CPB using sensitive measures of lung injury. ${ }^{25,26}$ Duration of prolonged mechanical ventilation was significantly higher in ONBEAT group. Theoretically, avoiding cardiopulmonary bypass should translate into less postoperative pulmonary dysfunction. Most randomized control trials show a definitive reduction in duration of ventilation, with early extubation after OPCAB. Patients of preexisting pulmonary disease are 
particularly benefited from OPCAB surgery. ${ }^{27,28}$ Patients in the OPCAB group compared to ONBEAT group had a significantly higher early postoperative LVEF, suggesting that the inflammatory response may be involved in the pathogenesis of post CPB cardiovascular dysfunction. ${ }^{29,30}$ The incidence of perioperative arrhythmia mostly atrial fibrillation (AF) was significantly higher in ONBEAT group. Atrial fibrillation occurs in $25-60 \%$ of patients after cardiac surgery. The role of OPCAB in influencing operative morbidity depends upon factors such as patient selection, surgeon experience and number of patients and further evaluation ${ }^{31}$.

The etiology of postoperative AF is multifactorial and exact pathogenesis of postoperative $A F$ in CABG patients is still not understood. However, $\mathrm{CPB}$ has been shown to be main independent predictor of postoperative AF in patients undergoing coronary revascularization. ${ }^{32}$ Regional ischemia due to atrial incision, and acute or chronic myocardial hypoperfusion may contribute to the development of AF by altering atrial conduction \& refractoriness. ${ }^{33}$ Hypomagnesaemia, which frequently occurs after $\mathrm{CPB}$, may induce post-operative $\mathrm{AF}^{34}$ Inflammatory events are also suggested to play a role in the pathogenesis of postoperative AF. The development of systemic inflammatory response syndrome (SIRS) with or without clinically proven infection has been shown to be an independent risk factor for new onset of tachyarrhythmias in particular AF, after cardiac surgery. ${ }^{35}$ Off-pump coronary bypass reduce the incidence of postoperative AF compared with CABG on cardiopulmonary bypass. ${ }^{36-40}$ This is probably secondary to the blunted systemic inflammatory response, avoidance of atrial cannulation, and reduce myocardial ischemia in OPCAB.

In more than a decade or so OPCAB has been tested through an increasingly rigorous process of scientific validation. From a large number of observational, case-matched, retrospective analysis to randomized controlled trials, there is plenty of evidence that OPCAB surgery is now proven, safe cost-effective and reproducible surgical technique. Finally, as the study was done in a single center by single surgeon, caution should be exercised to generalize the findings to reference population.

\section{CONCLUSION:}

OPCAB was associated with lower operative morbidity compared to ONBEAT cardiac surgery. However, intraoprative conversion from OPCAB to ONBEAT CABG significantly increases operative morbidity \& mortality, because haemodynamically unstable patients or patients with frequent ventricular fibrillation are often switched to ONBEAT group. But on-pump CABG can be performed safely on high risk patients. Use of cardiopulmonary bypass and elimination of cardioplegic arrest may be beneficial to hemodynamically unstable patients. The study indicated that OPCAB is associated with a significant reduction in blood loss and transfusion requirement, better myocardial function, reduced incidence of post operative arrhythmia, less post operative pulmonary dysfunction and pneumonia.

\section{REFERENCES:}

1. Roach GW, Kanchuger $M$, Mangano $C M$, Newman $M$, Nussmeier N, Wolman R, Aggarwal A, Marschall K, Graham SH, Ley C. Adverse cerebral outcomes after coronary bypass surgery. Multicenter Study of Perioperative Ischemia Research Group and the Ischemia Research \& Education Foundation Investigators. N Engl J Med 1996;335(25):1857-63.

2. Tuman KJ, McCarthy RJ, Najafi H, Ivankovich AD. Differential effects of advanced age on neurologic and cardiac risks of coronary artery operations. J Thorac Cardiovasc Surg 1992;104(6):1510-7.

3. Corwin HL, Sprague SM, DeLaria GA, Norusis MJ. Acute renal failure associated with cardiac operations. A case-control study. J Thorac Cardiovasc Surg 1989;98 (6):1107-12.

4. Hilberman M, Derby GC, Spencer RJ, Stinson EB. Sequential pathophysiological changes characterizing the progression from renal dysfunction to acute renal failure following cardiac operation. J Thorac Cardiovasc Surg $1980 ; 79(6): 838-44$.

5. Butler J, Rocker GM, Westaby S.Inflammatory response to cardiopulmonary bypass. Ann Thorac Surg. 1993;55 (2):552-9. 
6. Fremes SE, Weisel RD, Mickle DA, Ivanov J, Madonik MM, Seawright SJ, Houle S, McLaughlin PR, Baird RJ. Myocardial metabolism and ventricular function following cold potassium cardioplegia. J Thorac Cardiovasc Surg. 1985;89(4):531-46.

7. Al-Ruzzeh S, Ambler G, Asimakopoulos G, Omar RZ, Hasan R, Fabri B, El-Gamel A, DeSouza A, Zamvar V, Griffin S, Keenan D, Trivedi U, Pullan M, Cale A, Cowen M, Taylor K, Amrani M; Off-Pump Coronary Artery Bypass (OPCAB) surgery reduces risk-stratified morbidity \& mortality: a United Kingdom Multi-Center Comparative Analysis of Early Clinical Outcome. Circulation 2003;108 Suppl 1:111-118.

8. Cleveland JC Jr, Shroyer AL, Chen AY, Peterson E, Grover FL.Off-pump coronary artery bypass grafting decreases risk-adjusted mortality and morbidity. Ann Thorac Surg 2001;72(4):1282-8; discussion 1288-9.

9. Buffolo E, de Andrade CS, Branco JN, Teles CA, Aguiar LF, Gomes WJ. Coronary artery bypass grafting without cardiopulmonary bypass. Ann Thorac Surg 1996;61 (1):63-6.

10. van Dijk DI, Nierich AP, Jansen EW, Nathoe HM, Suyker WJ, Diephuis JC, van Boven WJ, Borst C, Buskens E, Grobbee DE, Robles De Medina EO, de Jaegere PP; Octopus Study Group. Early outcome after off-pump versus on-pump coronary bypass surgery: results from a randomized study. Circulation 2001;104(15):1761-6.

11. Mack MJ, Duhaylongsod FG. Through the open door! Where has the ride taken us? J Thorac Cardiovasc Surg 2002;124(4):655-9.

12. Sakata RI, Fujii Y, Kuwano H.Thoracic and cardiovascular surgery in Japan during 2008: annual report by The Japanese Association for Thoracic Surgery. Gen Thorac Cardiovasc Surg 2010;58(7):356-83. doi: 10.1007/ s11748-010-0604-0.

13. Arai H. Recent advancements in devices for off-pump coronary artery bypass grafting. Ann Thorac Cardiovasc Surg 2007;13(1):1-4.

14. Ascione RI, Lloyd CT, Underwood MJ, Lotto AA, Pitsis AA, Angelini GD. Inflammatory response after coronary revascularization with or without cardiopulmonary bypass. Ann Thorac Surg 2000;69(4):1198-204.

15. Xia L, Ji Q, Song K, Shen J, Shi Y, Ma R, Ding W, Wang $C$.Early clinical outcomes of on-pump beating-heart versus off-pump technique for surgical revascularization in patients with severe left ventricular dysfunction: the experience of a single center. J Cardiothorac Surg 2017 23;12(1):11. doi: 10.1186/s13019-017-0572-x.
16. Yuichi Izumi, Katsuaki Magishi, Noriyuki Ishikawa, Fumiaki Kimura. On-Pump Beating-Heart Coronary Artery Bypass Grafting for Acute Myocardial Infarction. Ann Thorac Surg 2006;81(issue 2):573- 576. DOI: http://dx.doi.org/10.1016/j.athoracsur.2005.08.036

17. Edmunds LH Jr1. Advances in the heart-lung machine after John and Mary Gibbon. Ann Thorac Surg 2003; 76(6):S2220-3.

18. Blauth CI, Cosgrove DM, Webb BW, Ratliff NB, Boylan M, Piedmonte MR, Lytle BW, Loop FD. Atheroembolism from the ascending aorta. An emerging problem in cardiac surgery. J Thorac Cardiovasc Surg 1992; 103(6):1104-11; discussion 1111-2.

19. Hannan EL, Wu C, Smith CR, Higgins RS, Carlson RE, Culliford AT, Gold JP, Jones RH. Off-pump versus on-pump coronary artery bypass graft surgery: differences in short-term outcomes and in long-term mortality \& need for subsequent revascularization. Circulation 2007;116(10):1145-52.

20. Edgerton JR, Dewey TM, Magee MJ, Herbert MA, Prince $\mathrm{SL}$, Jones KK, Mack MJ. Conversion in off pump coronary artery bypass grafting ; an analysis of predictors and outcomes. Ann thorac surg 2003;76:1138-42

21. Landoni G, Pappalardo F, Crescenzi G, Aletti G, Marchetti C, Poli D, Franco A, Rosica C, Zangrillo A. The outcome of patients requiring emergency conversion from off pump to on pump coronary artery bypass grafting. Eur J Anaesthesial 2007;24:317-22.

22. Tabata M, Takanasi S, Harai T, Fukui T, Hosoda Y. Emergency conversion in off pump coronary artery bypass grafting. Interact Cardiovasc thorac Surg 2006; 5:555-9.

23. Stamou SC, Jablouski KA, Hill PC, Bafi AS, Boyce SW, Corso PJ. Coronary revascularization without cardiopulmonary bypass versus conventional approach in high risk patients. Ann thorac surg 2005;79:552-7.

24. Laffey JG, Baylan JG, Cheng DC. The systemic inflammatory response to cardiac surgery: Implication for anesthesiologist. Anesthesiology 2002;97:215-52.

25. Rady MY, Ryan T, Starr NJ. Early onset of acute pulmonary dysfunction after cardiovascular surgery: Risk factors and clinical outcome. Critical care Med 1997;25:1831-9.

26. Sinclair DG, Haslam PL, Quinlan GJ, Pepper JR, Evans TW. The effect of cardiopulmonary bypass on intestinal and pulmonary endothelial permeability. Chest 1995; 108:718-24 
27. Guler M, Kirali K, Toker ME Bozbuga N, Omeroglu SN, Akinci $E$, et al. Different CABG methods in patientswith chronic obstructive pulmonary disease. Ann thorac Surg. $2001 ; 71: 152-7$.

28. Kochamba GS, Yun KL, Pfeffer TA, Sintec CF, Khonsari S. Pulmonary abnormalities after coronary arterial bypass grafting operation: Cardiopulmonary bypass versus mechanical stabilization. Ann Thorac Surg 2000; 69:1466-70.

29. Edmunds LH Jr. Inflammatory response to cardiopulmonary bypass. Ann thorac surg 1998;66:512-6.

30. Haltler Bg, Gorcsan J 3rd, Shah N, Oddis CV, Billiar TR, Simmons $R L$, et al. A potential role for nitric oxide in myocardial stunning. J Card surg 1994;9(3 suppl): 425-9.

31. Palin CA, Kailasam R, Hogue CW Jr. Atrial fibrillation after cardiac surgery:Pathophysiology and treatment. Semen cardiothorac vasc Anaesth 2004;8:175-83.

32. Ascione R, Caputo M, Calori G, Lliyd CT, Underwood MJ, Angelini GD. Predictor of atrial fibrillation after conventional and beating heart coronary surgery: a prospective randomized study. Circulation 200;102:1530-5.

33. Adams DC, Heyer EJ, Simon AE, Delphin E, Rose EA, OZMC et al. Incidence of atrial fibrillation after mild or moderate hypothermic cardiopulmonary bypass. Crit care Med 2000;28:309-11.

34. Miller S, Cristal E, Garfinkle M, Lau C, Lashevsky L, Cannolly SJ. Effect of magnesiumon atrial fibrillation after cardiac surgery: a meta-analysis. Heart 2005; 91: 618-23.
35. Mayr A, Knotzer H, Pajk W, Luckner G, Ritch N, Dunber $M$, et al. Risk factor associated withnew onset tachyarrythmias after cardiac surgery-a prospective analysis. Acta Anaesthesiol scand 2001;45:543-9.

36. Chen DC, Bainbridge D, Martin JE, Novick RJ: Evidence - based perioperative clinical outcomes Research group. Does off pump coronary bypass reduce mortality, morbidity, and resourse utilization when comaired with conventional coronary artery bypass? A meta- analysis of randomized trials. Anaesthesiology 2005;102;188 $-203$.

37. Reston JT, Tregcar SJ, Turkelson CM. Meta-analysis of short-term and midterm outcomes following off pump coronary artery bypass grafting. Ann Thorac surg 2003; 76:1510-5.

38. Raja SG, Behranwala AA, Dunning J. Does off pump coronary artery surgery reduce the incidence of post-operative atrial fibrillation? Interact cardiovasc thorac Surg 2004;3:647-52.

39. Athannasiou T, Aziz O, Mangoush O, Al- Razzeh S, Nair $S$, Malinovski et al: Does off pump coronary bypass reduce the incidence of post-operative atrial fibrillation? Aquestion revisited. Eur J Card-Thorac Surg 2004; 26:701-10.

40. Athenansiou T Azziz O, Mangoush O, Weerasinghe A Al -Ruzzeh S, Purkayastha S, et al. Do off pump technique reduce the incidence of post operation atrial fibrillation in elderly patients undergoing coronary artery bypass grafting? Ann Thorac Surg 2004;77:1567-74. 